\title{
The Mind of Lincoln: Brilliance and Melancholy - A Video Production Capturing the Essential Healing Power of Positive Social Interactions in a Taped Drama
}

\author{
Diana J Semmelhack*, Colleen L Barron and Kate Gall \\ Downers Grove, Illinois, USA \\ *Corresponding author: Diana J Semmelhack, Downers Grove, Illinois, USA
}

\begin{abstract}
ARTICLE INFO
Received: 幽 August 09, 2019

Published: 幽 August 22, 2019

Citation: Diana J S, Colleen L B, Kate G. The Mind of Lincoln: Brilliance and Melancholy - A Video Production Capturing the Essential Healing Power of Positive Social Interactions in a Taped Drama. Biomed J Sci \& Tech Res 20(5)-2019. BJSTR. MS.ID.003502.
\end{abstract}

\begin{abstract}
If a picture paints a thousand words, then perhaps a video can paint ten thousand more. The work and actions of producing this dramatic video illustrate the development of positive interactions, and how these interactions lead to the improved mental health of adults with Severe Mental Illness (SMI). At the same time, internal and external stigma can be "busted" by increasing self-efficacy for the individual and challenging societal views of negative stereotypes. The example of this drama which was written, performed and produced by individuals with SMI can provide these individuals a manner to play a fundamental role in their treatment. Thus, allowing them to increase positive interactions leading to more fully functioning lives and providing them with the opportunity to continue on a journey of self-actualization.
\end{abstract}

Keywords: Drama therapy; Severe Mental Illness; Positive Interactions; Self-Efficacy; Stigma Busting

\section{Introduction}

Innovative ideas that shape society come from individuals considered to be mentally ill. Artists, writers, and deep thinkers such as Vincent Van Gogh, Virginia Wolf, Winston Churchill and Abraham Lincoln (A. Adkins, National Alliance of Mental Illness, NAMI, personal communication, September 13, 2017). Today, the population of adults with SMI residing in long-term care facilities continues to grow (National Center for Health Care Statistics, 1999) with few treatment options other than medication management [1]. These adults with SMI experience internal and external stigmatization. Internalized stigma, or self-stigma, exists on an individual level and can be described as a process where individuals with SMI endorse, internalize and eventually identify with negative stereotypes about mental illness [2].

External stigma exists at a societal level and these norms are often adhered to by institutions, groups, family members and staff who work with this population. These societal norms and institutional policies dehumanize and depersonalize these individuals through actions and interactions [3].Research supports the positive therapeutic impact on individuals with SMI including the ability to both internally and externally destigmatize their experiences about themselves and how others perceive them $[4,5]$. Morena [6] defines psychodrama as "the science which explores the truth of the psyche or mind" (p.12). Psychodrama, or drama therapy allows individuals to explore their minds and obtain important skills used in everyday communication through the use of drama, such as role playing or improvisational exercises. For example, an individual typically will not behave or speak the same way in front of their parents as they would with friends.

As such, individuals take on roles based on the contexts in which they find themselves and the people with whom they interact, and it is important for these individuals to realize that different contexts require different portrayals of themselves. Therefore, the benefits can include the increase of social skills, active hope and self-efficacy as well as the reduction of self-stigma and the improvement of coping skills. Not only is drama used in a cathartic manner for the actors, but the audience is able to identify with the character and feel their own emotions through those characters [5]. Videotaping of a dramatic event allows for reinforcement of the skills learned as well as mirroring and positive reinforcement by additional audience 
members and the performers themselves. The 8.5-minute video of "The Mind of Lincoln: Brilliance and Melancholy, 2015" captures the genius and struggles of one of the greatest Presidents in the United States along with the self-efficacy, creativity and courage of the performers with SMI.

Concurrently, the video highlights how positive interactions between cast, staff, audience members, and videographers can produce empathy, a safe holding environment and multi-voiced communication-interactive structures that are in stark contrast to the depersonalization and dehumanization that individuals with SMI are frequently exposed to by societal norms, institutions and other individuals [3]. The video consists of interviews of cast and crew members, as well as highlights of the show and captures the healing power of the fine arts. Three of the main characters interviewed for the video included "Mrs. Mary Lincoln Todd", "a Union Soldier" and "Abraham Lincoln". Their interviews reflected the importance of the positive impact of performing on themselves and their loved ones, being able to give a voice to people without one, and the achievements past and potentially in the future of this population which can contribute positive change in society.

Underlying this paper is the conclusion that: The social interaction of people diagnosed with SMI plays a fundamental role in their mental health and treatment-ultimately facilitating their capacity to be creative human beings [3]. The use of drama and video are creative ways to facilitate these positive interactions. We demonstrated how positive interaction structures (including

ISSN: 2574-1241

DOI: 10.26717 /BJSTR.2019.20.003502

Diana J Semmelhack. Biomed J Sci \& Tech Res

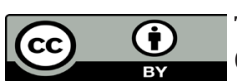

This work is licensed under Creative Commons Attribution 4.0 License

Submission Link: https://biomedres.us/submit-manuscript.php the development of a containment and holding environment, the development of a culture of enquiry, sharing of power and multivoiced conversations contributed to the creation of a therapeutic production, The Mind of Lincoln: Brilliance and Melancholy performed and developed by 22 individuals diagnosed with SMI and housed in a long term care facility. Lincoln suffered from severe depression and serves as a prime example of how someone with a mental illness can make a superior contribution to society. The 8.5-minute video highlights the healing effects of the fine arts and the ability of healing positive interactions portraying more than ten thousand words.

\section{Reference}

1. Semmelhack D, Ende L, Hazell C (2013) Group Psychotherapy with Severely Mentally ill Adults: Adapting the Tavistock Method. London: Routledge.

2. Corrigan P, Markowitz FE, Watson A, Rowan D, Kubiak MA (2003) An attribution model of public discrimination towards persons with mental illness. Journal of Health and Social Behavior 44(2): 162-179.

3. Semmelhack D, Ende L, Freeman A, Hazell C, Barron CL, et al. (2015) The Interactive World of Severe Mental Illness: Case Studies of the US Mental Health System, New York: Routledge.

4. Cohen JL, Johnson JL, Orr P (Eds.). (2015) Video and filmmaking as psychotherapy: Research and practice. Routledge.

5. Pellicciari A, Rossi F, Iero L, Di Pietro E, Verrotti A, et al. (2013) Drama therapy and eating disorders: A historical perspective and an overview of a Bolognese project for adolescents. The Journal of Alternative and Complementary Medicine 19(7): 607-612.

6. Moreno JL (1946) Psychodrama (1): 12-20. New York: Beacon House.

$\begin{array}{ll}\text { BIOMEDICAL } & \text { Assets of Publishing with us } \\ \text { RESEARCHES } & \text { Global archiving of articles } \\ & \text { - Immediate, unrestricted online access } \\ \end{array}$

